\section{OBSERVING OBJECTIVE, STRUCTURE, CLINICAL EXAMINATIONS (OSCE)}

Objective, structure, clinical examinations (OSCE) are increasingly used to examine clinical skills in both undergraduate and postgraduate students in the UK (1). As suggested by their name, the OSCEs are intended to reduce subjectivity amongst examiners by having predefined marking. This objectivity of marking as well as the structure of the examination, where all students are asked to answer the same questions and perform the same procedures, is intended to make OSCEs 'fairer' than other types of clinical examinations, such as short and long cases (2).

I have now taken part in six OSCEs - four as a clinical medical student and two as a 'sim', or simulated patient. My first experience on the other side of the couch was as a young woman who wanted to start taking the contraceptive pill. Fourth year medical students had to determine whether or not I was an appropriate candidate for the pill and explain to me how to take it and what to do if I missed one. More recently, third year dental students were asked to perform an extra- and intra oral examination on me. As a postgraduate student trying to get by on something similar to the minimum wage, the incentive of $£ 9$ an hour to do almost nothing is irresistible. Although it makes for a rather mind, or mouth, numbing morning, being a sim patient can have its interesting aspects.

In terms of advice for students, I learned two key things. Firstly, remembering to introduce yourself can make the difference between passing and failing (3). In both exams, specific marks were allotted for introducing yourself and confirming the patient's identity. Secondly, communication skills (3). In the medical exam, there were three marks assigned to 'overall impression'. These weren't awarded for knowledge but for confidence, demeanor and ability to put the patient at ease and treat with respect.

In addition, I also have a number of reflections on the whole process of OSCEs. To begin with, I feel a small sense of injustice that I never had the chance to take part in an OSCE as a sim patient before, rather than after, taking part as a student. Having the opportunity to observe a number of individuals perform exactly the same task gives you a very good sense of what works and what doesn't. Everyone has to develop a clinical style that they feel comfortable with. Being on the receiving end of a number of different approaches to the same problem is a great way of identifying just what aspects you might want to incorporate into your own style.

OSCEs could, therefore, be used as a learning experience for one group of students at the same time as an examination procedure for another. Undergraduate, like postgraduate students, are a willing and constant source of labor. Disclosure of exam contents from student sim patients should be of no concern since (4) it is easy enough to find out what appeared in last year's OSCE by simply asking someone who took it.

Next, there were one or two dental students who managed to hurt me. Not hurting the patient is a golden rule of exams, and clinical medicine in general. However, the OSCEs that I have taken part in had no way of assessing distress caused to patients. It would have taken minimal training and time to ask me to mark each student on their gentleness and include this at the bottom of the examiner's mark sheet. In fact, there are numerous examples in the literature, particularly from the USA, where sim patients are trained to do some or all of the marking at OSCE stations (5-7). This not only allows the patients to comment on 'how it was for them', but can also remove the need for a separate examiner altogether if sim patients are trained to perform all the marking. In turn, this can make OSCEs cheaper and easier to run, as fewer clinical staff are required.

Lastly, the OSCEs that I have taken part in as a medical student have provided no real opportunity for feedback on my performance. Whilst one of the main aims of exams, particularly in the later stages of the course, is to confirm that students will make safe practitioners $(8,9)$, failing to provide feedback beyond an overall mark is a wasted opportunity. The General Medical Council has recently emphasized the need for formative (where students are given feedback on their performance), as well as summative (where students are graded on their performance) assessments in medical education (10). One of the identified benefits of OSCEs are the opportunities they give for formative assessment and feedback (2).

OSCEs are an opportunity for each individual student to be observed by experts in a number of different clinical encounters. It makes sense to make use of this unique opportunity to provide all students with an assessment of their performance that goes beyond pass or fail. Again, there are examples of this in the literature, particularly from the USA, where students are given feedback either after the exam or as part of each OSCE station $(2,5)$. One possible way of providing individualized feedback would be to ask examiners to write, or dictate, a few sentences on each student between stations. These notes could then be transcribed, collated and returned to students with their 
marks. Such a procedure would not be particularly onerous and would allow students to learn from the experience of the OSCE, as well as the preparation beforehand.

OSCEs were first trialed in 1975 (11) and despite varied responses from both staff and students (12-16), they look set to stay with us. Although they are undoubtedly an improvement on the old 'long cases' in terms of fairness (1), the current use of OSCEs in the UK seems to present a number of missed opportunities in terms of both education and efficiency.

Jean Adams, BMedSci, MBBS

School of Population and Health Sciences

University of Newcastle upon Tyne

\section{ACKNOWLEDGEMENTS}

Many thanks to Prof. John Spencer and Dr. Martin White (both of Newcastle University) for engaging in discussions that help shape the arguments presented in this article.

\section{REFERENCES}

1. Wass V, Jones R, Van der Vleuten C. Standarised or real patients to test clinical competence? The long case revisited. Medical Education 2001;35:321-325.

2. Carraccio C, Englander R. The objective structured clinical examination: a step in the direction of competancy-based evaluation. Archives of Pediatrics and Adolescent Medicine 2000;154(7):736-741.
3. Wass V. Getting through OSCEs. Student BMJ 2000;8(9):361362.

4. Varma S. Should candidates be given their marked up papers back after examinations - the case for. Student BMJ 1999;7(11):456.

5. Duerson M, Romrell L, Stevens C. Impacting faculty teaching and student performance: nine years' experience with the objective structured clinical examination. Teaching and Learning in Medicine 2000;12(4):176-182.

6. Merrick H, Nowacek G, Boyer J, Robertson J. Comparison of the objective structured clinical examination with the performance of third-year medical students in surgery. American Journal of Surgery 2000;179:286-288.

7. Mavis B. Does studying for an objective structured clinical examination make a difference. Medical Education 2000;34:808-812.

8. Weetman A. Should candidates be given their marked up papers back after examinations - the case against. Student BMJ 1999;7(11):457.

9. Kaufman D. Assessing medical students: hit or miss. Student BMJ 2001;9(3):87-88.

10. Tomorrow's Doctors: Recommendations on Undergraduate Medical Education. July 2002. http://www.gmcuk.org/global_sections/sitemap_frameset.htm

11. Harden R, Stevenson M, Wilson Downie W, Wilson G. Assessment of clinical competence using objective structured examination. British Medical Journal 1975;1:447-451.

12. Kearney P. OSCEs don't work. Student BMJ 2000;8(3):123.

13. Green T. OSCEs are useful to assess particular skills. Student BMJ 2000;8(4).

14. Morris C. Objective structured clinical examination. Student BMJ 2001;9(7):303.

15. Mottram V. Objective structured clinical examination. Student BMJ 2000;8(2):82.

16. Phillips S. OSCE oscars. Student BMJ 2000;8(4):168.

Jean Adams is in the second year of a three year PhD research fellowship at Newcastle University, UK. She graduated in medicine in 2001 and also has a BMedSci degree in health psychology and psychiatry. Her current research focus is socio-economic inequalities in health but she also has a wider interest in health behaviours and health promotion.

\section{IRB REFORM IN NORTH AMERICA: CHALLENGES AND OPPORTUNITIES}

Clinical research is necessary to advance medical knowledge and to test new drugs or devices. It is therefore vital to society, and ethically imperative, that clinical studies be performed if patients are to have access to safe and effective treatments. However, clinical research by its very nature involves risk. Subjects who volunteer in clinical studies may receive no benefit; in fact, they may be seriously harmed or even die as a result of their participation. Indeed, research-related injuries and deaths, though relatively few in number (1), have become the subject of much controversy in recent years (2). Thus, protection of human research subjects must be given the highest priority by researchers, their institutions, and the government and regulatory bodies charged with overseeing the clinical research process. Central to this process is the institutional review board (IRB) in the United States (U.S.), or research ethics board as it is known in Canada. (For the purpose of this paper, the term "IRB" will be used to refer to both American and Canadian boards.) The IRB has frequently been referred to as the "first line of defense" in research subject protection (3), yet the specific roles and responsibilities of this board and its members are not clear (4). Defining these roles and responsibilities is more important now than ever before, for several reasons.

\section{THE ISSUES:}

IRBs in crisis

First, biomedical science is advancing at an unprecedented rate, and the number of clinical studies is 